\author{
Military Technical College \\ Kobry Elkobbah, Cairo, \\ Egypt.
}

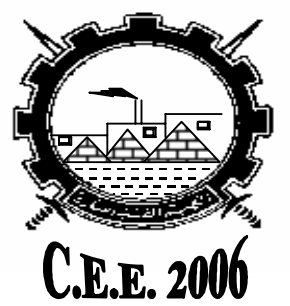

$3^{\text {rd }}$ International Conference

On

Chemical \& Environmental

Engineering

\title{
NANO-HYDROXYAPATITE FOR ENVIRONMENTAL APPLICATIONS
}

\author{
Ismail W. A. ", Fayed M. Sh. ${ }^{* *}$, Gouda Sh. R. ${ }^{* * *}$ and Awwad S. A. ${ }^{* *}$
}

\begin{abstract}
Nano-Hydroxyapatite (HAp) - polyvinyl alcohol (PVAL) gel was synthesized under pH control. The polyvinyl alcohol was used as the organic carrier for precursor ceramic gel. The ability of the formed hydroxyapatite - polyvinyl alcohol nanocomposite gel for the removal of heavy metals and radioactive nuclides from the environmental calibration standard (ECS) solution was analyzed by inductively coupled plasma mass spectrometer (ICP-MS). The effect of the temperature on the ions removal from ECS solution was studied at various temperatures of $25,35,40^{\circ} \mathrm{C}$. Additionally, the time for complete ions removal was studied between 10 to $45 \mathrm{~min}$. The recorded results showed the success of the gel in complete removal of all ions of the heavy metals and radioactive nuclides after 45 minute of contact with ECS solution at room temperature.
\end{abstract}

\section{KEY WORDS}

Nano Hydroxyapatite, lons removal, Heavymetal, Radioactive.

\footnotetext{
* National Research Center

** Egyptian Armed Forces

${ }^{* * *}$ Elmaadi Modern Academy.
} 


\section{INTRODUCTION}

A wide range of physical and chemical processes had been used for the removal of heavy metals from wastewater, such as electro-chemical precipitation, ultrafiltration, ion exchange and reverse osmosis [1-3]. However, some techniques are not economically appealing because of their high operational cost. Using commercial activated carbon can remove heavy metals from wastewater, such as $\mathrm{Cd}, \mathrm{Ni}, \mathrm{Cr}$ and $\mathrm{Cu}$ [4-7]. The contamination of groundwater and surface water by heavy metals from mining operations, industrial sites or from abandoned disposal sites has a dangerous effect on the environment. It has been determined that heavy metals are toxic to mammals, even within low levels of in water is a concern primarily because the heavy metal ions tend to bioaccumulate in the food chain. Therefore, considerable effort has been spent in treating metal-containing wastes at their source and the removal of heavy metal was reported for hydroxyapatite (HAp) [12-14]. It is well documented that hydroxyapatite strongly sorbs uranium and many other radionuclides and heavy metals [15-19].

The basic calcium phosphate known as Hydroxyapatite, $\mathrm{Ca}_{5}(\mathrm{OH})\left(\mathrm{PO}_{4}\right)_{3}$ (HAp), is well known as the mineral constituent of heard tissues bones and teeth. It is probably most well known for its use in the biomedical field[8-11]. Many industrial applications, are such as gas sensor, ion exchange, fuel cells and catalysis. Hydroxyapatite has been investigated as a potential agent to treat heavy metal-contaminated soils, sediments, wastes, and wastewater, especially in the cases of $\mathrm{Pb}, \mathrm{Cd}, \mathrm{Zn}$, and $\mathrm{U}[20-$ 21]. Also synthetic hydroxyapatite was used for the selective separation of Sr, Cs and $\mathrm{Ag}$ from nuclear wastes [22-23]. It was reported that nanosize range admits to get new physical and chemical properties. At nano level the properties are affected by the laws of atomic physics, rather than having as traditional bulk materials do. Also the surface properties of interfaces of nanosize differ than larger size [24].

A synthetic polymer-HAp composite was derived by preparing HAp in polymeric media (polymer matrix) without any chemical interaction between organic-inorganic interface. This lead to the formation of HAp in nanoscale. Nitrate ions, as cation sources for oxide ceramic powder, become oxidizing agents for the decomposition of PVAL. Also the metal ion-ligand complex based polymer precursors, which is very suitable for complex mixed oxide systems and in using for complexing agent to keep homogeneous distribution of metal ions through the matrix [25].The advantages of this technique are, low processing temperature, high molecular level homogeneity, improved purity, morphology, texture, and a scope to tailor made compound.

In this work nano HAp was synthesis by an inexpensive and simple technique by using, polyvinyl alcohol (PVAL) as the polymeric carrier. The effect of the formed HAp-PVAL naoncomposite gel was investigated for removal of heavy metal ion and radioactive nuclides in ECS solution. The relation between time and the efficiency of removal of heavy metal ion was recorded. Also the effect of the temperature on the removal process was verified. 


\section{EXPERIMENTAL}

\section{1-Chemicals:}

The chemicals used are calcium nitrate tetrahydrate $\left(\mathrm{Ca}\left(\mathrm{NO}_{3}\right)_{2} \cdot 4 \mathrm{H}_{2} \mathrm{O}\right.$, Mwt. $236.15 \mathrm{~g} / \mathrm{mole}$, Merk, Germany), di ammonium hydrogen ortho phosphate (anhydrous $\left(\mathrm{NH}_{4}\right)_{2} \mathrm{HPO}_{4}, 132.06 \mathrm{~g} / \mathrm{mole}, \mathrm{S}$.D. Fine Chem.Ltd. Mumbai), poly vinyl alcohol (PVAL) (M wt. $\approx 160000 \mathrm{~g} / \mathrm{mole})$ and ammonium hydroxide $\left(\mathrm{NH}_{4} \mathrm{OH}\right.$, Mwt. 35.5g/mole, May \& Baker, England). They were used in the experimental work without further purification. Environmental Calibration standard (ECS) containing 25 elements , Agilent, USA) was used as supplied in $30 \mathrm{ppm}$ of elements ( $\mathrm{Na}, \mathrm{Mg}, \mathrm{K}, \mathrm{Ca}, \mathrm{Fe})$ and 300 ppb of elements (Be, Al, V, Cr, Mn, Co, Ni, Cu, Zn, As, Se, Mo, Ag, Cd, Sb, Ba, $\mathrm{Pb}, \mathrm{TI}$, Th and $\mathrm{U}$ ) The range of the elements to be tested is within a concentration of ppm or ppb depending on their natural environmental presence.

\section{2-Instrumentation:}

Inductively coupled plasma mass spectrometry (ICP-MS) HP 4500 was used for quantitative analysis of the 25 elements ( $\mathrm{Fe}, \mathrm{K}, \mathrm{Ca}, \mathrm{Na}, \mathrm{Mg}, \mathrm{Be}, \mathrm{Al}, \mathrm{As}, \mathrm{Ba}, \mathrm{Cd}, \mathrm{Co}$, $\mathrm{Cr}, \mathrm{Cu}, \mathrm{Mn}, \mathrm{Ni}, \mathrm{Pb}, \mathrm{Sb}, \mathrm{Se}, \mathrm{TL}, \mathrm{V}, \mathrm{Zn}, \mathrm{U}$ and Th) in ECS solution. The ICP-MS could analyse the trace (ppb-ppm) and ultra-trace (ppt) elemental analysis using argon plasma technique and MS unit for the detection of the selective ions. The ICP-MS was prepared for analysis by stabilized the flow of plasma and argon flow as a sample carrier in controllable vacuum values. The samples introduced into the plasma automatically according to the prepared program using auto sampler. The plasma is used to atomize and ionize the elements in a sample. The resulting ions are then passed through a series of apertures (cones) into the high vacuum mass analyzer. The elements are identified by their mass and the intensity of a specific peak in the mass spectrum is proportional to the amount of that element in the original sample. The sequence of analysis was performed by testing environmental calibration solution prepared from the calibration curve before sample analysis. The quantitative analyses were done by calibration curve comparison. Same operation conditions and plasma were taken into consideration in the analysis of stander solution and samples to be in the same run.

\section{3-The preparation of HAp-PVAL gel:}

The preparation procedure followed in this study to produce nano hydroxyapatite was essentially the same as that of S. Nayar et al [26]. A 5\% PVAL were prepared in 1-L flat bottom flask (dissolved in deionized water) while stirring and heated at $80^{\circ} \mathrm{C}$ for 30 min. After complete dissolution of PVAL, the calcium nitrate $\left(\mathrm{Ca}\left(\mathrm{NO}_{3}\right)_{2} \cdot 4 \mathrm{H}_{2} \mathrm{O}\right)$ was added while stirring and heating until complete dissoluation. Finally diammonium hydrogen ortho phosphate $\left.\left(\mathrm{NH}_{4}\right)_{2} \mathrm{HPO}_{4}\right)$ solution was added to the mixture with $\mathrm{Ca} / \mathrm{P}$ atomic ratio 1.67 while stirring and heating at $80^{\circ} \mathrm{C}$, under $\mathrm{pH}$ controlled to be at 8 using ammonium hydroxide until the gel was formed. Detailed experiments were carried out to investigate the parameter affecting the synthesis to achieve HAp form, (concentration of PVAL, $\mathrm{Ca} / \mathrm{P}$ ratio, heating temp., $\mathrm{pH}$, stirring, adding sequence,...etc reported elsewhere [27]). Fig.1 shows the flow chart of the selected conditions for preparation of HAp gel. 


\section{4- Removal of elements:}

The effect of HAp gel amount on the removal of heavy metals ion from ECS solution was followed by adding various volumes of the produced HAp gel (10, 20, 30, 40, 50 and $60 \mu \mathrm{l}$ ) to $4 \mathrm{ml}$ of ECS solution. The supernatant clear solution was separated and analyzed by ICP-MS. The effect of time was studied by preparing seven vials, each vial contained $4 \mathrm{ml}$ of ECS solution then the optimum amount of the gel $(50 \mu \mathrm{l})$ was added to each vial. The supernatant was decanted at different times $(10,15,20,25$, 30,40 and $45 \mathrm{~min}$ ) and analyzed by ICP-MS. Finally the effect of temperature on the system was studied by adding $50 \mu$ l of the gel to $4 \mathrm{ml}$ ECS solution warmed at 25, 30 and $40{ }^{\circ} \mathrm{C}$. Again the supernatant solution was decanted and analyzed by ICP-MS at constant time interval and the results were recorded.

\section{RESULTS AND DISCUSSION}

The produced gel was dried and characterized by FTIR, SEM and XRD to confirm the hydroxyapatite formation as reported else where [27].

Fig 2 shows the effect of the gel concentration was studied through using different volumes $(10,20,30,40,50$ and $60 \mu \mathrm{l})$ to $4 \mathrm{ml}$ of ECS solution. It has to be notified that initial concentration recorded on the $y$-axis are for the elements tested in the ECS solution in parallel as a control. The differences from the data obtained compared to the ECS are within reasonable range.

The results show that, slightly reduced concentration of the elements in parallel with the concentration of HAp gel. The optimum amount of HAp gel was proved to be $50 \mu \mathrm{l}$, above which the elements concentration increased. This may be due to the effect of the gel on the homogeneity of the ECS solution. Also the concentration of $\mathrm{Ca}^{2+}$ ions (Fig 2a) increased as the gel increased until $50 \mu$ due to the presence of $\mathrm{Ca}^{2+}$ in $\mathrm{HAp}$ structure. Thenafter a reduced concentration is recorded even within higher gel content which is due to the incorporation in the gel. From these results shown in fig 2 it was observed that the adding of HAp gel slightly reduced the concentration of ions in the ECS solution.

Therefore the effect of the HAp gel persistence time was studied (Fig 3). The concentration of the elements decreased as the time increased for the constant amount of gel $(50 \mu \mathrm{l})$. There was no detection of elements even in ppb level after 45 min proving that the suitable time for complete removal is achieved after $45 \mathrm{~min}$.

The effect of temperature on the process was studied by warming the mixture of HAp gel in ECS solution from room temperature to $40^{\circ} \mathrm{C}$. It was found that, no remarkable effect, within the temperature rise from room temperature to $40^{\circ} \mathrm{C}$. This proves to the stability of the ECS solution which can be operated up to $40^{\circ} \mathrm{C}$. 
The above results are discussed in view of HAp may interact with metal ions in solution via these possible mechanisms: (1) lon-exchange mechanism, when a partial replacement of ions in the initial phosphate structure takes place without destruction of the latter; (2) Mechanism involving a chemical reaction, when the lattice of the initial compound is destroyed and new crystalline or amorphous products are formed [28]; and (3) Sorption mechanism in which the cation trapped in HAp structure [17]. The ion exchange mechanism of aqueous cations with synthetic hydroxyapatite is intensively studied, and reported that the reaction of synthetic hydroxyapatite and $\mathrm{Ba}, \mathrm{Cd}, \mathrm{Mg}, \mathrm{Ni}$ and $\mathrm{Zn}$ as nitrates was cation exchange based on structure, ionic radii, and stoichiometric ion replacement [29]. It was reported also $\mathrm{HAp}$ removed divalent heavy-metal ions via the ion exchange of $\mathrm{Ca}^{2+}$ ions of $\mathrm{HAp}$ [30].

In the present work the $\mathrm{Ca}^{2+}$ ions didn't increase by the increase of time removal of ions, and it was decreased gradually as time increased fig $3 a$, which means that the gel interact by sorption mechanism. The 25 elements used of ECS didn't slow the attainment of equilibrium, or reduce the capacity of removal. Also nano size of the used gel enhance the capacity of ions removal besides the presence of PVAL work as steric entrapment for cations leading to complete removal of the elements in the solution. It was reported that synthetic hydroxyapatite could reduce aqueous pb from $1000 \mathrm{mg} / \mathrm{l}$ to less than $1 \mathrm{mg} / \mathrm{l}$ [29]. Several studies are dealing with phosphate ionexchanger capacities [28]. The formed gel can be used as a seinterd disc for removal of ions via the ion exchange [30].

\section{CONCLUSION}

Nano-Hydroxyapatite (HAp) - polyvinyl alcohol (PVAL) gel was synthesized. An inexpensive polyvinyl alcohol polymer was used in a simple technique for the preparation. The formed hydroxyapatite - polyvinyl alcohol nanocomposite gel successfully removed all the heavy metals and radioactive elements from ECS after $45 \mathrm{~min}$ at room temperature. The increase of the mixture temperature has no effect on the removal process due to the stability of ECS solution's within the operating temperature range. The present HAp-PVAL gel was successful in removing 25 elemental ions collectively from ECS, compared to previous studies. 


\section{REFERENCES}

[1]. S. Rengaraj, K. Yeon, and S. Moon, "Removal of chromium from water and wastewater by ion exchange resins", Journal of Hazardous Materials, Vol. 87, no. 1-3, p. 273-287, (2001).

[2]. L. Yurlova, A. Kryvoruchko and B. Kornilovich, "Removal of Ni (II) ions from wastewater by micellar-enhanced ultrafiltration", Desalination, Vol. 144, no. 255260, (2002).

[3]. Y. Benito, and M. Ruiz, "Reverse osmosis applied to metal finishing wastewater", Desalination, Vol. 142, no. 3, p. 229-234, (2002).

[4]. R. Ramos, J. Rangel, J. Mendoza, L. Fuentes, and R. Guerrero, "Adsorption of cadmium (II) from aqueous solution onto activated carbon", Water science and technology, p. 205-211, (1997).

[5]. J. Shim, S. Park, and S. Ryu, "Effect of modification with $\mathrm{HNO}_{3}$ and $\mathrm{NaOH}$ by pitch-based activated carbon fibers", Carbon,Vol. 39, no. 11, p. 1635-1642, (2001).

[6]. S. Oki, R. Neufeld, and R. Perry, "Use of activated carbon for the recovery of chromium from industrial wastewaters", Journal of Chemical Technology and Biotechnology, Vol. 70, no. 1, p. 3-8, (1997).

[7]. L. Monser, and N. Adhoum, "Modified activated carbon for the removal of copper, zinc, chromium, and cyanide from wastewater", Separation and Purification Technology, Vol. 26, no. 2-3, p. 137-146, (2002).

[8]. T. Nakano, A. Tokumura, and Y. Umakoshi, "Variation in Crystallinity of Hydroxyapatite and the Related Calcium Phosphates by Mechanical Grinding and Subsequent Heat Treatment", Metallurgical and materials transactions A, Vol. 33A, p.521, (2002).

[9]. D. Tadic, and M. Epple, "A thorough physicochemical characterization of 14 calcium phosphate-based bone substitution materials in comparison to natural bone", Biomaterials Vol.25, p. 987-994, (2004).

[10]. R. LeGeros, "Calcium phosphate ceramics in dentistry and medicine", Department of Metallurgy and Materials Engineering, Institute of Materials Science, university of Connecticut, Seminar Series, (2002).

[11]. S. Pathumarak, C. Lorprayoon, and W. Intiya, "Preparation and characterication of porous hydroxyapatite from Bovine bone used as bone substitute materials", 26th Congress on Science and Technology of Thailand, Bangkok, (2000).

[12]. H. Owada, K. Yamashita, T. Umegaki , T. Kanazawa and M. Nagai, "Humiditysensitivity of yttrium substituted apatite ceramics", Solid State Ionics, Vol. 35, p. 401-404, (1989).

[13]. W. Bostick, and R. Stevenson, "Use of Apatite and Bone Char for the Removal of Soluble Radionuclides in Authentic and Simulated DOE Groundwater", Advances in Environmental Research, Vol3, p. 488-498, (2000).

[14]. Y. Park and Y. Yamazaki, "The Development of High Crystalline Calcium Phosphate/Nafion Composite Membrane for Fuel Cell", $1^{\text {st }}$ International Conference on Polymer Batteries and Fuel Cells, (2003).

[15]. J. S. Arey, and J. C. Seaman, "Immobilization of Uranium in Contaminated Sediments by Hydroxyapatite Addition", Environmental Science and Technology, Vol. 33, p. 337-342, (1999). 
[16]. W. D. Bostick, and R. J. Stevenson, "Use of Apatite and Bone Char for the Removal of Soluble Radionuclides in Authentic and Simulated DOE Groundwater", Advances in Environmental Research, Vol3, p.488-498, (2000).

[17]. J. Jeanjean and J. Rochaud, "Sorption of Uranium and Other Heavy Metals on Hydroxyapatite", Journal of Radioanalytical and Nuclear Chemistry , Vol. 201, no.6, p. 529-539, (1995).

[18]. F. OrdonezRegil, E. Guzman, and E. Regil, "Surface Modification in Natural Fluorapatites After Uranyl Solution Treatment", Journal of Radioanalytical and Nuclear Chemistry, Vol. 240, no.2, p. 541-545 (1999).

[19]. "Solution for FERNALD treatment of uranium in brine ion exchange regeneration fluid", SCFA Lead Lab Technical Assistance \#143, Final report, August 26, (2002).

[20]. S. Singh, L. Ma, and W. Harris, "Heavy Metal Interactions with Phosphatic Clay: Sorption and Desorption Behavior", J. Environ. Qual., Vol. 30, (2001).

[21]. G. Lusvardi, G. Malavasi, L. Menabue and Monica Saladini, "Removal of cadmium ion by means of synthetic hydroxyapatite", Waste Management, Vol. 22, P. 853-857, (2002).

[22]. H. Leinonen, "Removal of harmful metals from metal plating waste waters using selective ion exchangers", Report Series in Radiochemistry No. 13 ,(1999).

[23]. S Lazic,.and Z. Vukovic, "lonexchange of strontium on synthetic hydroxyapatite", Journal of Radioanalytical and Nuclear Chemistry, Articles Vol. 149 , no.1, p. 161-168, (1990).

[24]. K. Hickman, "Nanomaterials", Cambridge scientific abstracts, (2002).

[25]. P. Pramanik, "Soft chemicals for high-tech materials", Department of chemistry, Indian institute of technology, Kharagpur, (2003).

[26]. S. Nayar, A. Sinha, "Systematic evolution of a porous hydroxyapatitepoly(vinylalcohol)-gelatin composite" Colloids and Surfaces B: Biointerfaces, Vol. 35, p.29-32, (2004).

[27]. S. Awwad " PhD thesis, chemistry and technology of advanced ceramics and its applications”, under reviewing, military technical college, Cairo (2006).

[28]. I. Shashkova, A. Rat'ko, N. Kitikova, "Removal of heavy metal ions from aqueous solutions by alkaline-earth metal phosphates", Colloids and Surfaces, Vol. 160, p 207-215 (1999).

[29]. W. Admassu, T.Breese, "Feasibility of using natural fishbone apatite as a substitute for hydroxyapatite in remediating aqueous heavy metals", Journal of Hazardous Materials B69, p.187-196, (1999).

[30]. J. Reichert, J. Binner, R. Sambrook and J. Cooper, "Effectiveness of hydroxyapatite for water filtration”, Third Euro-ceramics, Vol.3, p. 81-85, (1993). 


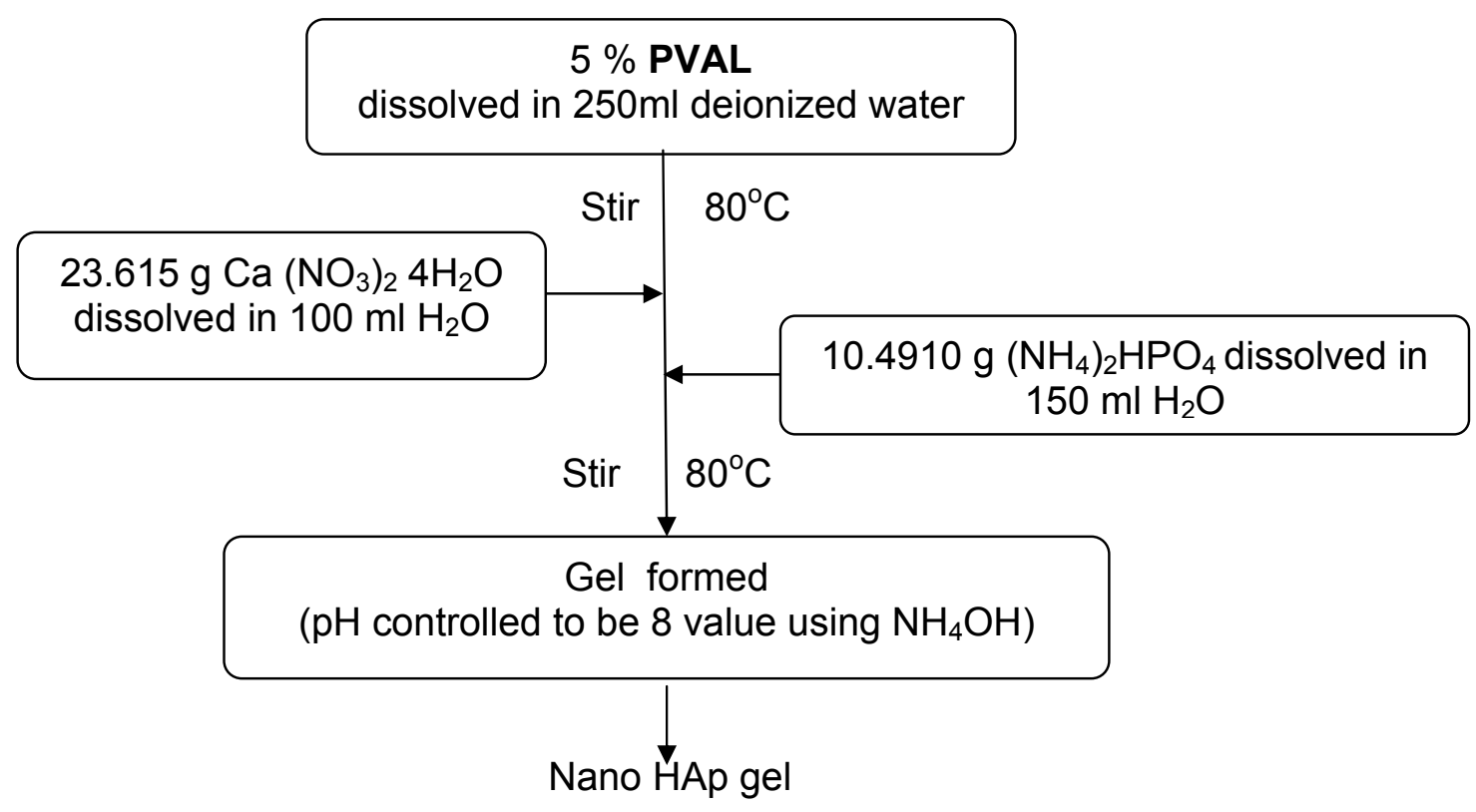

Fig. 1: The flow chart for the preparation of calcium phosphate powders prepared by PVAL method 


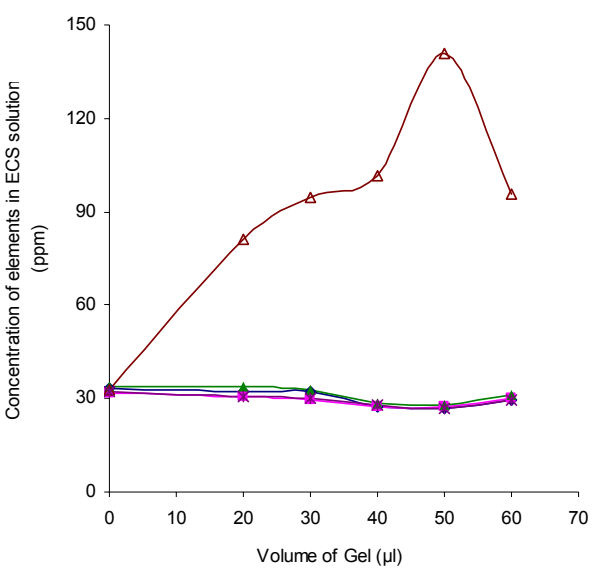

(a)

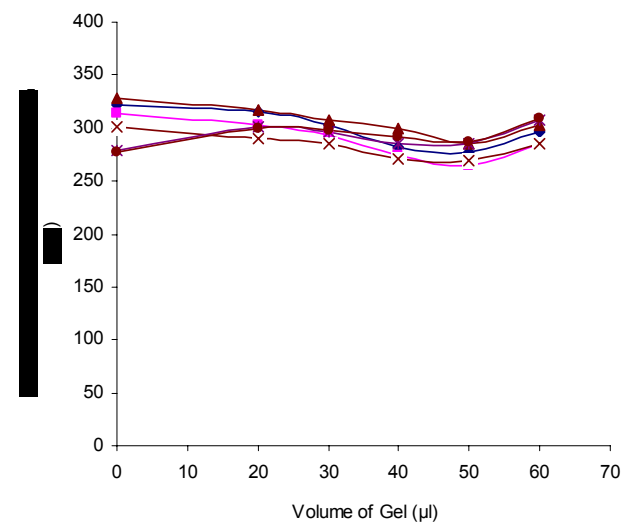

(c)

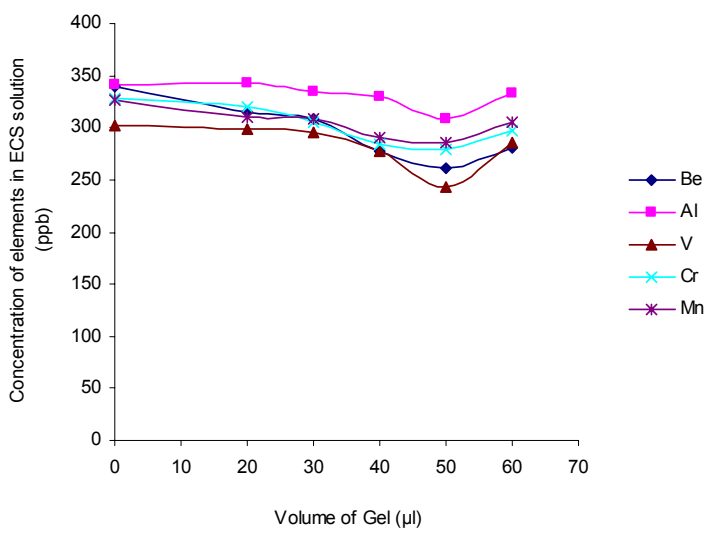

(b)

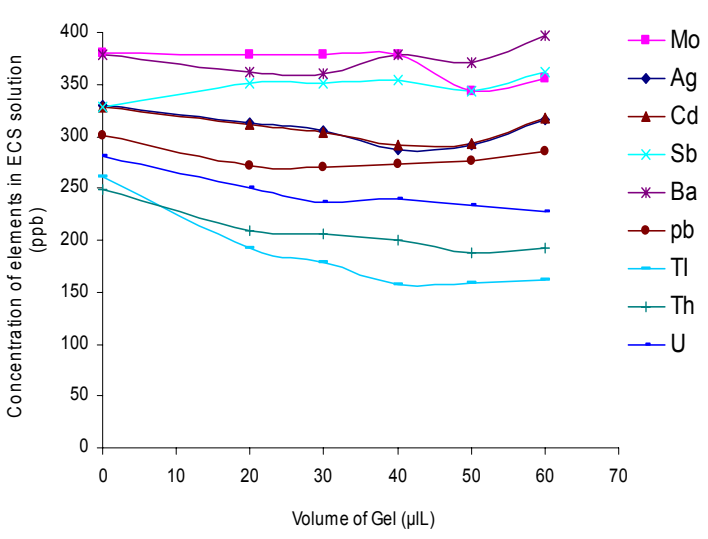

(d)

Fig. 2: The effect of gel concentration added with different volumes $(10,20,30,40,50$ and $60 \mu \mathrm{l})$ to $4 \mathrm{ml}$ of ECS solution. 


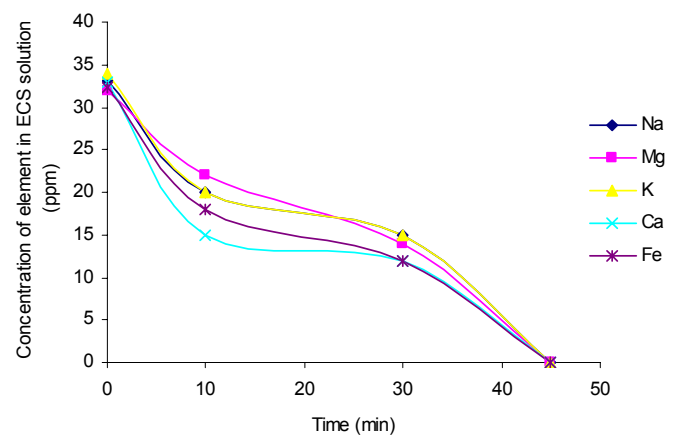

(a)

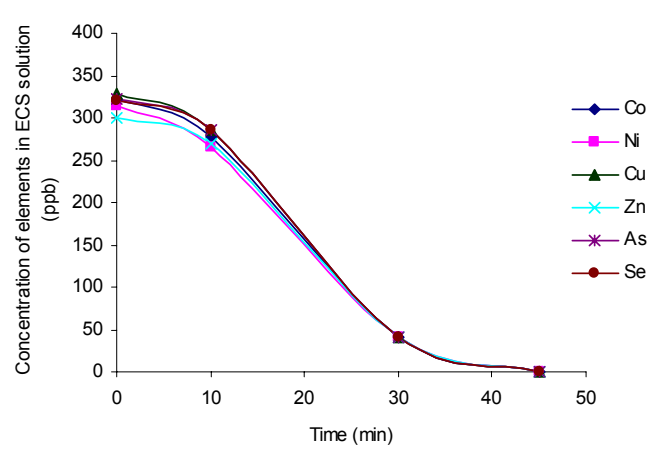

(c)

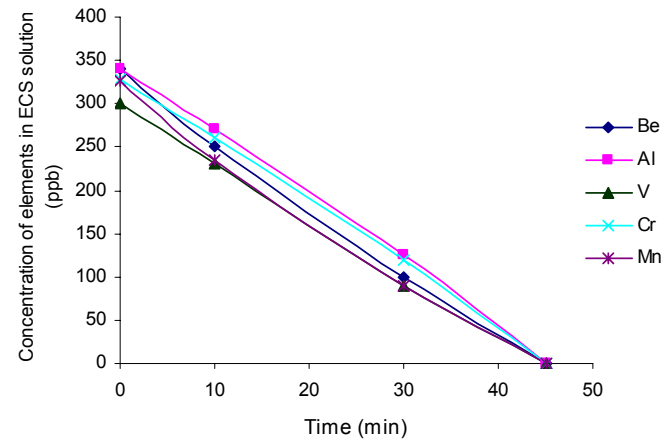

(b)

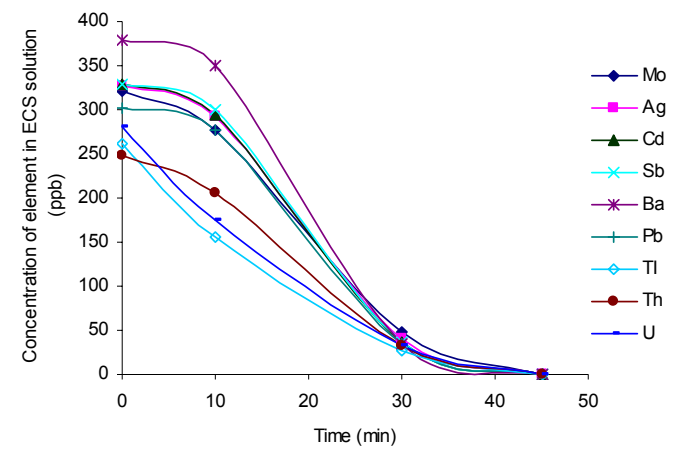

(d)

Fig. 3: The effect gel duration in the ESC solution. 